\title{
Correction to: 2018 Press Conference Records of Ministry of Ecology and Environment, the People's Republic of China
}

Correction to:

2018 Press Conference Records of Ministry of Ecology and Environment, the People's Republic of China, https://doi.org/10.1007/978-981-33-4806-6

The original version of the book was inadvertently published with an incorrect institution name. It has now been changed from "Ministry of Ecology and Environment" to "Ministry of Ecology and Environment of the People's Republic of China". The book has been updated with the change. 